\title{
Design and construction of high-rise modular buildings based on recent projects
}

Michael J. Hough BSc(Eng), MSc, CEng, MIStructE, MIEI Director, MJH Structural Engineers, Dublin, Ireland
R. Mark Lawson BSc(Eng), PhD, CEng, MIStructE, MICE Professor of Construction Systems, University of Surrey, Guildford, UK; The Steel Construction Institute, Guildford, UK

The technology of modular construction is developing rapidly. Information was therefore collected on recent mediumand high-rise projects to evaluate the state of the art of construction practice and to prepare design and construction guidance. This paper reviews the principles that guided the design, manufacture and construction of some recent highrise modular buildings in the UK. In the absence of specific design and execution standards for modular buildings, the paper shows how existing requirements for steel construction can be adapted for this new way of building. The paper also covers the economic arguments for modular construction and summarises factory production methods.

\section{Notation}

\section{$B \quad$ module width}

$G_{\mathrm{k}} \quad$ self-weight of the module $\left(\mathrm{kN} / \mathrm{m}^{2}\right)$

$H \quad$ height of the top of the $n$th level

$L \quad$ module length

$N_{\text {tie }} \quad$ horizontal tie force between the modules

$Q_{\mathrm{k}}^{\text {tie }} \quad$ imposed load acting on the module $\left(\mathrm{kN} / \mathrm{m}^{2}\right)$

$e_{\text {tot }} \quad$ deviation in verticality at the top of the $n$th level

$h$ module height

$n$ floor level under consideration

$\Psi$ reduction factor at the accidental limit state $(=0.5$ in residential buildings)

\section{Introduction}

Modular construction comprises prefabricated three-dimensional (3D) or volumetric units that are fitted out in manufacture and are installed on site as load-bearing 'building blocks'. It is mainly used in cellular-type buildings such as hotels, student residences and apartments, where the module size is compatible with room sizes and with transportation requirements.

The current application of modular construction of all types is reviewed by Lawson et al. (2014). Recent case studies are presented in this paper to demonstrate its use in high-rise residential buildings.

\subsection{Background to market demand}

There is a strong drive from the UK government to deliver more buildings through offsite manufacture (OSM). Goodier and Gibb (2007) highlighted the opportunities for OSM over 10 years ago. The House of Lords report (House of Lords Science and Technology Select Committee, 2018) is the most recent study on OSM, involving contributions from a wide range of stakeholders. The Farmer Review of the UK Construction Labour Market (Farmer, 2016) also showed how OSM can alleviate shortages in the labour market.

The UK Construction Industry Council (CIC, 2013) projected that building for social and private rent should rise to $35-40 \%$ of the total housing output to meet housing needs by 2020. It is these sectors that are most open to OSM and to modular construction in particular.

The UK Commission for Employment and Skills (UKCES, 2013) and the Construction Industry Training Board (CITB, 2017) also identified a strategy for training in the particular skills of OSM. Consultants KPMG (KPMG, 2016) and the National House Builders Council Foundation (NHBC Foundation, 2016) have also produced reports on the future impact of OSM on construction.

The total OSM sector is estimated (UKCES, 2013) at 7\% of UK construction output, which is itself about $7 \%$ of gross domestic product. The modular manufacturing part of the total OSM sector is probably about $5 \%$ but is growing. Buildoffsite has promoted this sector and produced a useful glossary of terms (Gibb and Pendlebury, 2006).

\subsection{Forms of modular construction}

There are two generic forms of modular construction, the selection of which affects the flexibility of possible solutions, particularly in terms of plan layouts. They are

- load-bearing modules in which loads are transferred through the walls of the modules that are often manufactured with partial open sides (Figure 1)

- corner-supported modules in which loads are transferred by way of edge beams to corner posts (Figure 2).

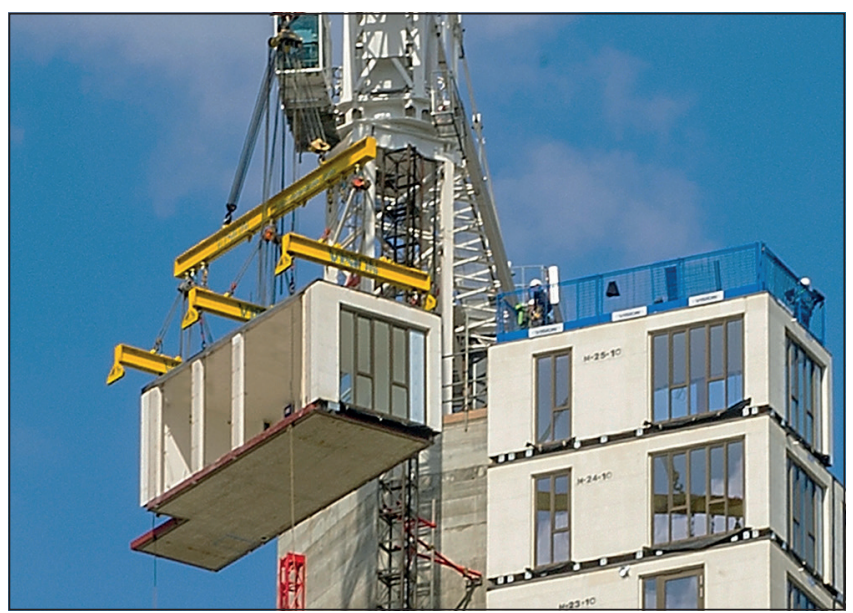

Figure 1. Installation of module with partially open sides (courtesy of Vision Modular Systems) 


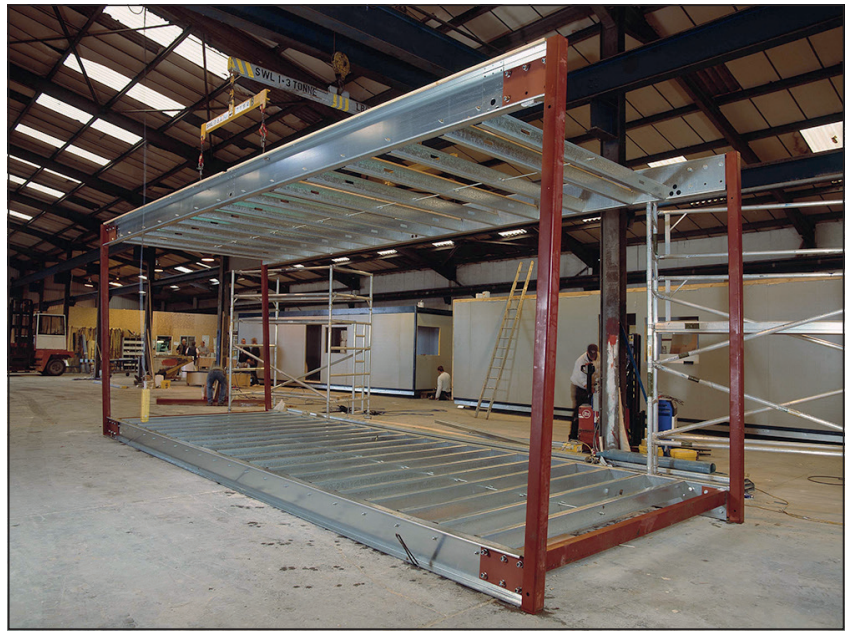

Figure 2. Fully open-sided module with corner posts (courtesy of Kingspan)

For load-bearing walls, light-steel C sections may be used in buildings up to 12 storeys high but smaller square hollow sections (SHS) are often required for high-rise buildings. For cornersupported modules, the compression resistance of the corner posts is the controlling factor and $100 \times 100 \mathrm{~mm}$ or $150 \times 150 \mathrm{~mm}$ SHS are the preferred size, except at the lower levels where larger posts may be required. For low-rise buildings, $80 \times 80 \mathrm{~mm}$ SHS may be used. The edge beam depth is related to the span and, for long modules, intermediate posts may be required.

The choice of the floor system is a further factor that affects the weight and stiffness of the modules. Joisted floors with 150-200 mm deep C sections are widely used for low- and medium-rise buildings and may be combined with a concrete screed. However, a concrete floor slab typically $150 \mathrm{~mm}$ deep with peripheral channel sections is often used for modules in high-rise buildings as it achieves $120 \mathrm{~min}$ fire resistance and high stiffness for spans up to $4 \cdot 2 \mathrm{~m}$. This is the system presented in the three case studies in this paper.

Clearly a balance has to be achieved between the module weight and the supporting structure of the modules. Resistance to horizontal forces, such as wind loads, and robustness to accidental actions become increasingly important with the scale of the building. The strategies employed to ensure adequate stability of modular assemblies, as a function of the building height, are

- diaphragm action of boards or bracing within the walls of the modules: suitable for 4- to 6-storey buildings

- integral bracing in the walls of the modules: X or V bracing in the side walls and $\mathrm{K}$ bracing in the facade walls

- diaphragm action of the profiled steel walls in container-type modules

- separate braced steel structure located around the lifts and stair area and at certain locations between the modules or end gables

- reinforced-concrete or steel-plated core: suitable for taller buildings.

Modules are tied at their corners so that they act together to transfer wind loads. The robustness requirements for modular construction are based on a 'localisation of damage' route, in which support to the modules is removed individually to assess the ability of the rest of the modular assembly to support the applied loads at the accidental limit state (see section 6.3).

A further issue in modular construction is that of installation and manufacturing tolerances, which can cause eccentricities in the compression load path and also lead to additional horizontal forces applied to the modules. These aspects are reviewed in Section 6.2.

\subsection{Sustainability benefits of modular construction}

There is a strong argument for the use of modular construction based on its sustainability benefits and on reducing disruption to the locality during the construction process. This is particularly important in confined sites or in hospitals or schools, where there are operational constraints on noise and transport movements in construction. Indeed, for this reason, lightweight modules are often used in roof-top extensions to medical facilities.

The sustainability arguments are related to the materials efficiency, reduced waste, improved working conditions and speed of construction. These have a direct impact on the economics of modular construction that are considered later. More reliable performance and the ability to commission equipment and services installations offsite before delivery are important. Modules can also be demounted, refurbished and re-used, which is important in 'pop-up' developments.

\section{History of high-rise modular buildings}

The definition of high-rise in the context of modular construction in the UK is generally taken as 11 or more storeys (or $30 \mathrm{~m}$ height), which corresponds to the change from 90 to 120 min fire resistance. At this height, questions of the compression resistance of the loadbearing elements of the module and stability to horizontal forces have a strong effect on the design solution.

The first example of high-rise modular construction was the Paragon project in west London, completed in 2006 (Figure 3).

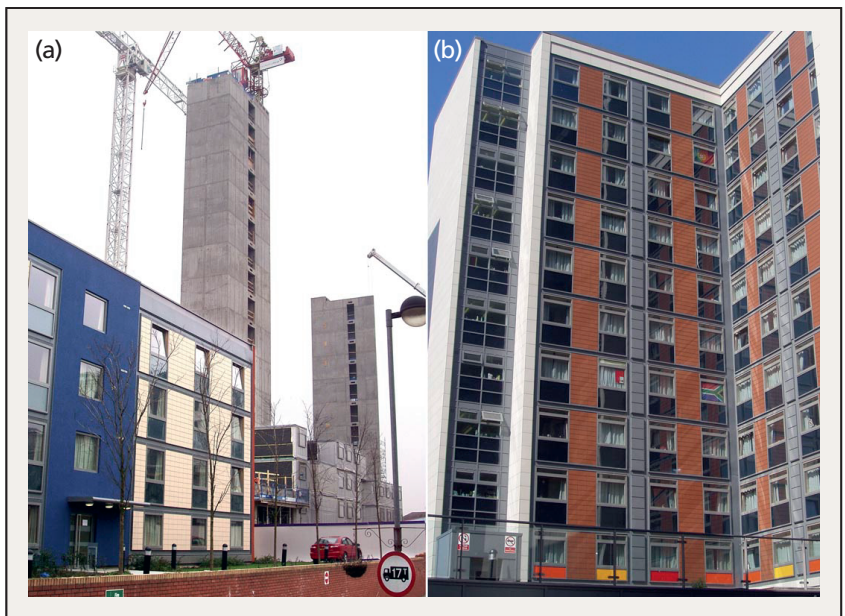

Figure 3. Paragon project, London: (a) construction of concrete core and installation of modules and (b) completed 11-storey student residence (courtesy of Caledonian Modular) 
It comprises six separate buildings of 4, 5, 7, 12 and 17 storeys in the form of one- and two-bedroom layouts for key workers and students. A wide range of module types was manufactured, many with open sides and integral corridors. In total, 827 modules were installed, including 413 in the 17 -storey building. The typical module size was $12 \mathrm{~m}$ long by $2.8 \mathrm{~m}$ wide, but some were up to $4.2 \mathrm{~m}$ wide. A concrete core provided the overall stability of the 17 -storey building.

The second notable project in the UK was a 25 -storey student residence in Wolverhampton (Figure 4). A total of 820 modules was installed in 9 months, and the overall construction period was only 15 months to meet the start of the academic year in August 2009. Two other buildings on the site were 8 and 11 storeys. The modules are supported at foundation level, and the 3rd, 7th, 12th and 18th floors are set back on one side and form a cantilever to the floors above. This cantilever is supported by a steel frame, which is independent of the modular units above. The techniques used in this project are explained in the case studies that are presented by Lawson et al. (2014).

A 32-storey residential building (named B2 in its construction) was completed at Atlantic Yards, New York in late 2016. It consists of 930 modules up to $10.7 \mathrm{~m}$ long and $4.3 \mathrm{~m}$ wide to create 363 apartments in different configurations. The construction of this complex high-rise building posed significant challenges, which resulted in delays and subsequent legal problems. This project highlighted the importance of high levels of accuracy in modular manufacture and installation, which was cited as one of the reasons why the project was delayed.

\section{Recent high-rise buildings}

\subsection{Case study 1: modular hotel and residential project}

A mixed private and affordable housing and hotel project was the first modular building to be completed in the regeneration of the 1920s Wembley industrial area in north London, UK. Located on the re-named Olympic Way, it was completed in May 2013. The project had three parts: a 12-storey hotel, a 20 -storey residential block with private apartments, and a connecting 5 -storey residential building for affordable housing. The 234-room hotel occupies the main frontage of the building and the lobby, restaurant and retail units are located below the podium level.

There were 700 modules in total, which were installed in three phases, starting with the hotel and ending with the tower block. In the connected oval-shaped tower block and the medium-rise residential part, a total of 68 one-bedroom, 71 two-bedroom and 19 three-bedroom apartments was provided. The modules in the hotel and medium-rise parts were supported on a $1 \mathrm{~m}$ thick concrete podium, and the modules in the tower were placed around an $8.2 \times 6.8 \mathrm{~m}$ concrete slip-formed core that was constructed in advance.

The modules were manufactured up to $3.9 \mathrm{~m}$ wide and $10.5 \mathrm{~m}$ long and consisted of a concrete floor with peripheral $150 \mathrm{~mm}$ deep channel sections and walls comprising $60-80 \mathrm{~mm}$ deep hollow sections. Two modules formed a one-bedroom apartment of $59 \mathrm{~m}^{2}$ floor area with an integral glazed balcony, and three modules formed a two-bedroom apartment of $76 \mathrm{~m}^{2}$ area. The module floor was also extended to form the corridors and patio, as shown in Figure 5, so that no site concreting was required. The completed

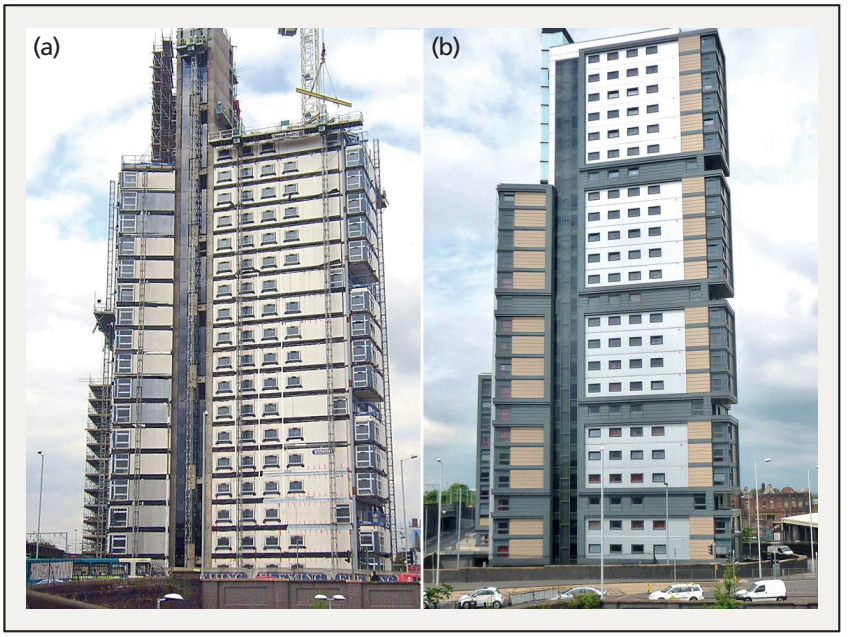

Figure 4. Wolverhampton student residence: (a) 25-storey building during construction; (b) completed building (courtesy of Vision Modular Systems)

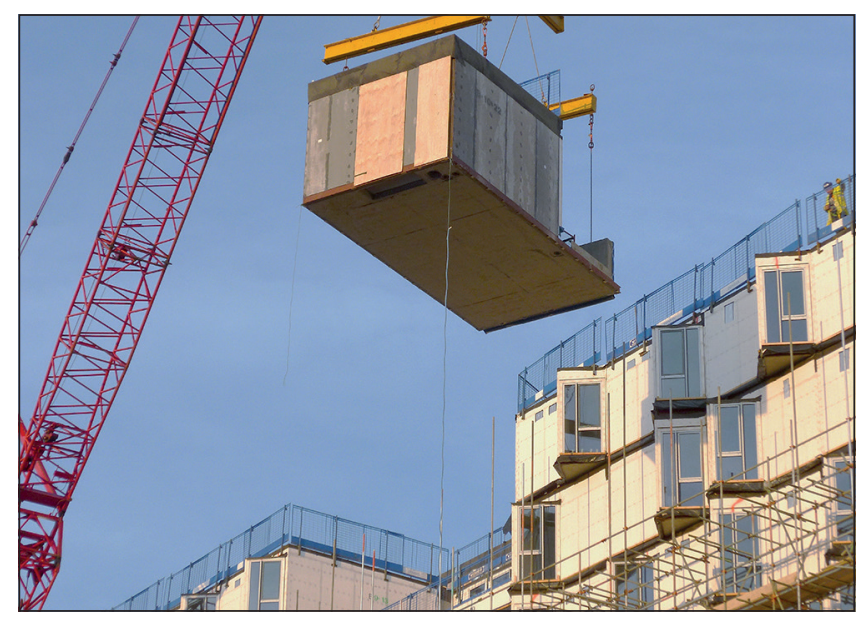

Figure 5. Installation of module with an extended floor for an integral terrace

hotel is shown in Figure 6(a). In the oval-shaped tower block, the modules had a variety of shapes, as shown in Figure 6(b).

The cladding to the hotel and street-side apartments consists of horizontal format terracotta tiles that were fixed to the face of the modules by way of secondary rails. In the facade walls, the oriel windows were manufactured as part of the modules and their positions were offset on each floor. In the oval tower, the balconies were attached to the module floors.

\subsection{Case study 2: Apex House, Wembley}

Apex House is a 28-storey student residence in Wembley, London (Figure 7). Because of its confined site, the project required justin-time delivery of modules, cladding panels and so on. This novel project required a step change in thinking about the design of modular buildings, including the tight tolerances required in modular manufacture and in the construction of the slip-formed core. 


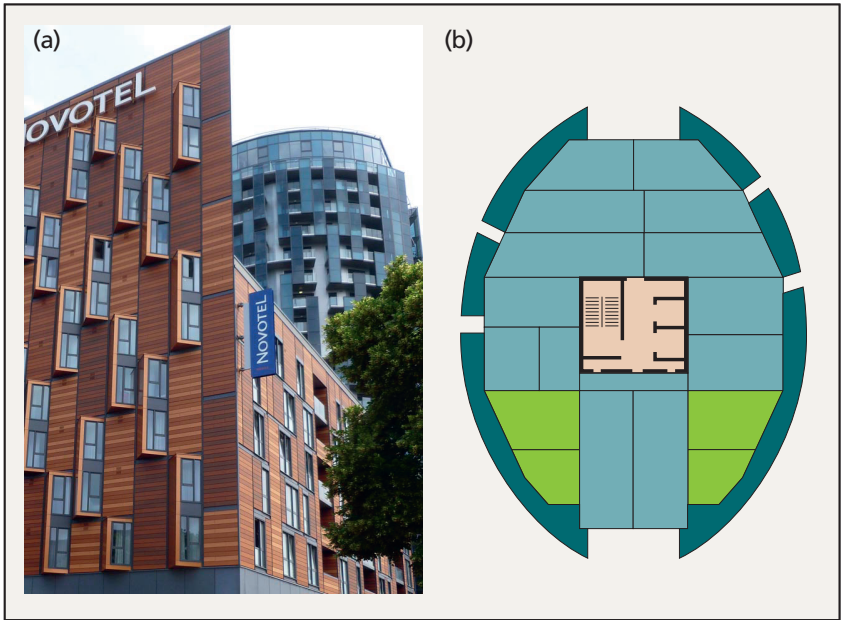

Figure 6. Hotel and residential building on Olympic Way, Wembley: (a) hotel with tower block in the background; (b) varying shape of modules used in the oval-shaped tower (courtesy of Tide Construction and Vision Modular Systems)

The installation of the 679 modules took place over a 16-week period in early 2017 and the overall construction period was only 11 months from foundations to handover to the client. The total floor area excluding the basement was $15400 \mathrm{~m}^{2}$ of which the modular area was approximately $85 \%$. The central core was only $7.5 \mathrm{~m}$ square and its $300 \mathrm{~mm}$ thick slip-formed concrete walls provided stability for the $82 \mathrm{~m}$ high modular building.

The study bedroom modules also included a connected corridor, and final boarding of the corridor was made on site using boards delivered with the module. A linear group of five or six modules and the larger module for the kitchen and communal space was serviced from the core by way of the corridor. The modules in the 'wings' of the building also have braced steel frames located between them to aid in overall stability. The modules placed around the core are connected directly to the core.

Most study bedroom modules were $2.7 \mathrm{~m}$ wide and $7.3 \mathrm{~m}$ or $9 \mathrm{~m}$ long. Some modules were $4.1 \mathrm{~m}$ wide and were classified as 'wide loads' and had to be delivered outside peak hours. Modules were produced at a maximum rate of 50 per week, and 300 modules were manufactured in advance of start on site, to be installed in the required sequence. Production then kept pace with installation. The glass-reinforced cement cladding was installed by using mast climbers connected to the modules so that internal and external work could proceed together.

The building had a combined heat and power system located in the basement and photovoltaic panels on the roof, and was one of the first modular buildings to achieve an 'excellent' Breeam environmental rating (Breeam, 2019).

\subsection{Case study 3: Mapleton Crescent, Wandsworth}

Mapleton Crescent is a 25 -storey modular residential project between Garratt Lane, Wandsworth, south London and the Wandle River (Figure 8). It comprises 53 one-bedroom units as well as 26 two-bedroom and 10 three-bedroom units and, on completion in May 2018, was the tallest modular building in Europe.

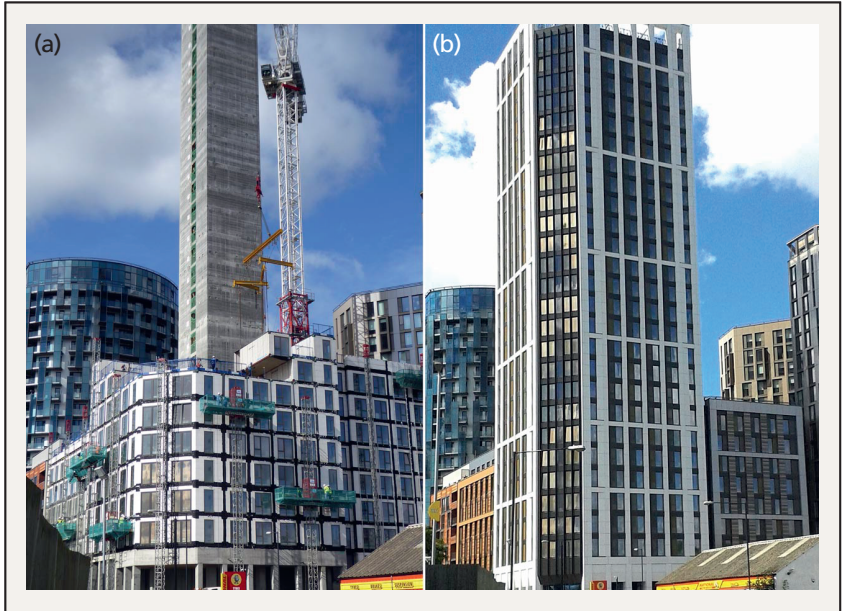

Figure 7. Apex House, Wembley: (a) during construction; (b) completed (courtesy of Tide Construction and Vision Modular Systems)

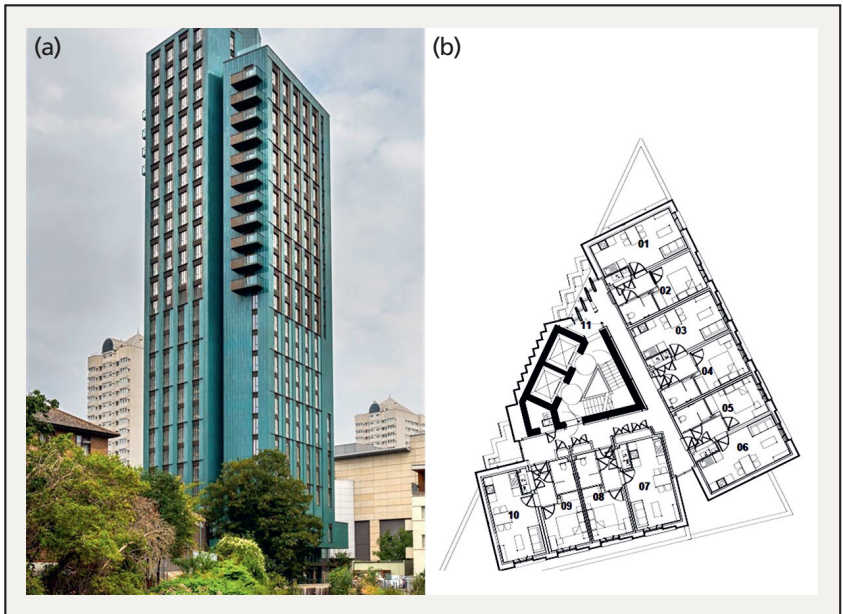

Figure 8. Mapleton Crescent, Wandsworth: (a) completed building; (b) typical plan form (courtesy of Tide Construction and Vision Modular Systems)

Originally conceived in reinforced concrete, the plan layout was designed to be suitable for modular production without affecting the client's requirements. The triangular building form was designed with five or six single-bedroom apartments per floor from levels 2 to 11, three two- or three-bedroom apartments per floor from level 12 and a penthouse on the top two levels. Modules were typically 3.2 or $3.5 \mathrm{~m}$ wide and $6.5 \mathrm{~m}$ long. Two modules created a $38 \mathrm{~m}^{2}$ single-bedroom unit, three modules created a two-bedroom unit of $68-72 \mathrm{~m}^{2}$ area and four modules created a three-bedroom unit of $81-83 \mathrm{~m}^{2}$ area. This flexibility in layout was achieved by the partially open-sided modules.

The 22 and 24 floors of modules are supported on a $1.8 \mathrm{~m}$ thick concrete podium at first floor that houses all the communal space below and cantilevers to one side. The slip-formed concrete core is also triangular in shape and provides the overall stability of the 
building as well as housing two 'turbo-lifts' and pre-cast concrete stairs.

The first modules were installed in July 2017. A total of 252 modules were delivered and installed at a rate of eight modules per day. The balconies were also attached on site to the preformed 'stubs' included in the floors of the modules. The modules in the larger apartments had under-floor heating, which required finishing work on site.

The green ceramic cladding was manufactured in the form of large format tiles with a wave-like appearance. Cladding was installed by way of mast climbers connected to the modules. The overall construction programme of 18 months saved an estimated 12 months relative to flat slab concrete construction.

\subsection{Future buildings}

A further high-rise modular building is underway in Croydon, UK. The two towers use 1500 modules and the construction system extends the systems developed in the above case studies.

\section{Economic argument for OSM against on- site construction}

In OSM, the additional costs of a manufacturing facility and dedicated workforce are balanced against tangible savings in more efficient and less wasteful site processes that modular construction provides. The economic benefits of OSM of modular systems arise from

- economy of scale in manufacture (dependent on production volume)

- reduced material use and less wastage and site disposal costs

- higher productivity in manufacture and less work on site

- higher quality and reduced 'snagging' and re-working costs

- savings in site management costs (known as site preliminaries)

- savings in external fees as the detailed design is made by the modular supplier

- financial benefits to the client and contractor by speed of installation.

Most modular construction projects involve a significant proportion of on-site work, with $30-50 \%$ being typical in construction cost terms. The UK National Audit report (NAO, 2005) stated that on-site work for a fully modular building (without a podium or core) could be broken down into foundations (5\%), on-site services $(8 \%)$, cladding and roof finishes $(10 \%)$ and internal work $(7 \%)$, as a proportion of the total building cost. For a highrise building with a core and podium similar to those described in the case studies, the installed cost of the modular units may be only $50 \%$ of the total building cost. The on-site work has a direct effect on the efficiency of the module installation, so careful coordination is essential, particularly in terms of the accuracy of the on-site and manufactured components.

Although the personnel involved in installation of the modules is typically only 10 to 16 , the number of site personnel in other activities reflects the rapid nature of the process. Nevertheless, in the case study projects, the total number of site personnel was less than $50 \%$ of those required for fully on-site construction. Reducing waste on site and recycling waste in the factory are also important drivers in modular construction.

It is widely recognised that savings of $30-50 \%$ in total construction time can be achieved by using modular construction. The economic value of this early completion depends on the particular business operation and the reduced cash flow and additional revenue. This can be readily quantified for a hotel chain or a time-constrained operation, such as a university or hospital. Furthermore, site management costs are typically reduced from $15 \%$ to $8 \%$ in proportion to the shorter construction programme.

A study was made of the actual construction programme of the 25-storey modular building in Wolverhampton (Lawson et al., 2012), which is shown in simplified form in Figure 9. The modules were delivered at a rate of six to ten a day and, during concreting of the cores, approximately six concrete wagons were scheduled daily to achieve a construction rate of one storey every 3 days.

\section{Factory production of modules}

Manufacturing of modular units can take many forms, from the simplest assembly of modules in a static position to a sophisticated production line system. Mullen (2011) describes the factory design of timber modules. The production of steel-framed modules has to be flexible to create a range of building layouts but, in any production system, it is necessary to standardise on the structural elements, boards and services.

The output of modules from one factory that is economically viable can range from approximately 500 to 2000 a year. In choosing the optimum production method, a balance has to be achieved between improved productivity and capital investment against manufacturing flexibility. Manufacturers aiming at varied and more flexible modular production runs tend to adopt static or less sophisticated forms of linear production. Manufacturers targeting high-volume repetitive buildings, such as hotels and student residences, tend to use more advanced production systems. The three main forms of manufacturing system are termed here as 'static', 'linear' and 'semi-automated linear' production.

Static production means that the modules are manufactured in one position, and materials, services and personnel are brought to the module. The space around the modules for local storage of materials is typically five times the module area.

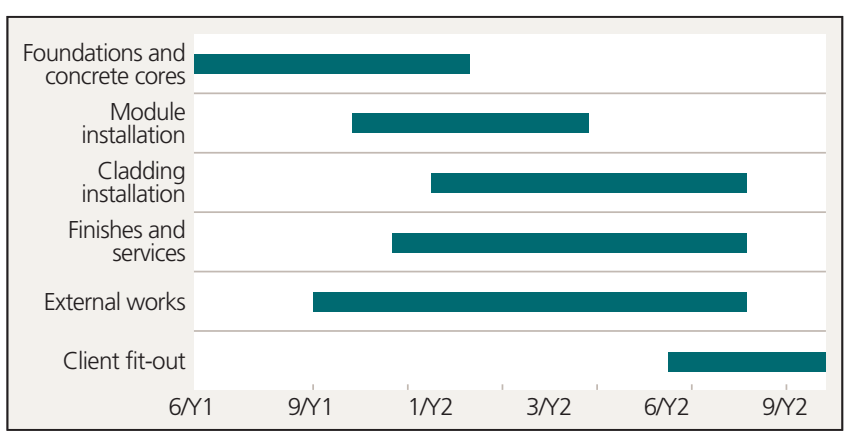

Figure 9. Simplified construction programme for the Wolverhampton project 
When completed, the module is lifted out by overhead crane and then either stored temporarily or transported directly to site. Typically, in a medium-sized factory, up to 30 modules are in production at any one time. The cycle from assembly to completion is generally $6-10 \mathrm{~d}$, and so the average production rate is three to four modules a day, equivalent to a maximum output of 1000 modules a year.

Linear production means that the manufacturing process is carried out in a number of individual stages. The first stage is the manufacture of the wall, floor and ceiling panels, which are then assembled into $3 \mathrm{D}$ units. The verticality of the walls is generally controlled by an L-shaped jig. The modules may be manufactured on wheels or trolleys and moved between stations by electrical vehicles, motorised trolleys, or on roller tracks, where their size permits. The number of production stages reflects defined operations, such as plaster-boarding, installation of bathroom pods and decorating. In designing the facility, the time involved in each stage should be similar to avoid bottlenecks, and to balance the dwell time at each stage on the line.

Semi-automated linear production has separate lines for manufacture of wall, ceiling and floor panels. The speed of manufacture of panel lines has to be matched against the more manual operations at the end of the production line. An illustration of four stages in a linear manufacturing process is shown in Figure 10, in which turning tables are introduced in stage 3 so that the panels can be boarded on both sides in stages 2 and 4 . The initial investment in semi-automated production may be $£ 10$ 15 million in addition to the factory space. For production of 1000 modules a year and amortised over 4 years, this may represent an investment of $10 \%$ of the ex-works cost of a module. However, this investment leads to more efficient production and reduced labour costs in manufacture.

\section{Structural action of groups of modules}

The structural behaviour of an assembly of modules is different to structural frames because of the multiple interconnections between the modules. The design of modular systems is not covered by design codes and so the starting points are Eurocodes and execution standards for structural frames, with some adaptations considering the particular features of this new form of construction. The key factors to be taken into account in the design of high-rise modular buildings are

- the influence of manufacturing and construction tolerances on the additional forces acting on the modules

- effects due to the sway stability of the group of modules

- the mechanism of force transfer of horizontal loads to the concrete core

- robustness to accidental actions (also known as structural integrity).

The most efficient structural form of high-rise buildings is where the modules are clustered around a concrete core, as shown in Figure 11. In this example, the 16 modules form eight similar onebedroom apartments and most have integral balconies. Modules are accessed from corridors built as part of the core and all but the corner modules are directly connected to the core.

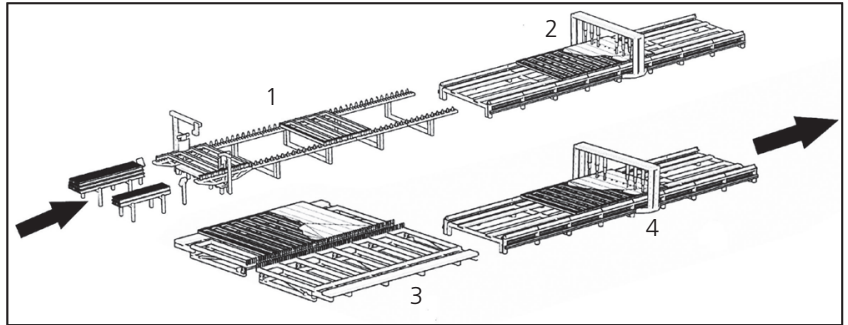

Figure 10. Example of semi-automated line for wall and ceiling panels. 1: Framing station; 2: working table with multi-function bridge for boarding on one side; 3 : turning table; 4 : working table with multi-function bridge for boarding on the opposite side

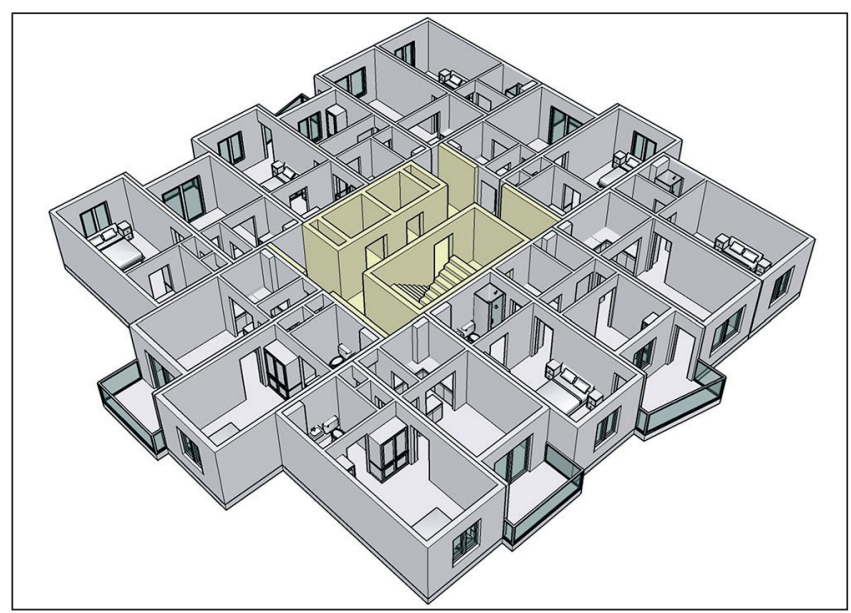

Figure 11. Modules clustered around a concrete core (courtesy of HTA Design)

Designers should consider the limits on construction tolerances for modular buildings that influence their design, as set out in the following sections.

\subsection{Influence of constructional tolerances}

For multi-storey steel frames, BS EN 1090-2 (BSI, 2008) permits an out-of-verticality of $h / 500$ for individual columns, where $h$ is the floor-to-floor height, but the cumulative deviation over a number of storeys is $H /\left(300 n^{0.5}\right)$, where $H$ is the height of the $n$th level. However, the tolerances used for steel frames are not necessarily appropriate for modular construction. Also, because of the need to control second-order effects in high-rise modular buildings, more precise control of geometry is required that also includes construction of the concrete core.

Therefore, the following recommendations for control of deviations of a group of modules relative to a datum level are proposed separately for medium- and high-rise buildings. In this context, the definition of high-rise is taken as buildings of 12 or more storeys from the first modular level (as this may start from a podium level).

Manufacturing deviations may lead to slight out-of-verticality of the modules and also to small variations in length and width. For modules used in low- and medium-rise buildings, the maximum 
permitted deviation in geometry may be taken as illustrated in Figure 12. The out-of-verticality and deviation in length in manufacture may be taken as $h / 500$ or a maximum of $6 \mathrm{~mm}$. However, it is important that this maximum deviation is not repeated systematically in the manufacture of all modules.

Added to this manufacturing deviation is the possible eccentricity in module installation. The alignment of the upper module relative to the top of the module below should be controlled to a maximum of $6 \mathrm{~mm}$ on a given level, but this can be corrected over a number of modules relative to datum. If the positional and manufacturing eccentricities are combined, the permitted cumulative deviation to the top of the $n$th module may be taken as proposed by Lawson and Richards (2010), as follows

1. $e_{\mathrm{tot}}=12 \sqrt{n-1} \leq 40 \mathrm{~mm}$

The upper limit on out-of-verticality relative to datum is taken as $40 \mathrm{~mm}$ for modules 12 storeys high. The design gap between the modules should be a minimum of $50 \mathrm{~mm}$ to allow for some closure between adjacent modules, but clearly this is not sufficient if the maximum deviations are in opposite directions. Some manufacturers design for smaller gaps but this requires greater control of accuracy.

The same general approach may be used for high-rise modular buildings, but in this case, control of deviations relative to datum level should be more precise. It is proposed that the out-ofverticality in manufacture of a module may be taken as $h / 1000$ or a maximum of $3 \mathrm{~mm}$, which requires more precise control of geometry, often involving a jig to maintain verticality. For high-rise buildings, it is proposed that the permitted cumulative deviation of the top of the $n$th module may be taken as

2. $e_{\mathrm{tot}}=8 \sqrt{n-1} \leq 40 \mathrm{~mm}$

For the 12th level, this leads to a maximum deviation of $26 \mathrm{~mm}$ from datum (rather than $40 \mathrm{~mm}$ for an equivalent medium-rise building). A maximum deviation of $40 \mathrm{~mm}$ relative to datum should be used for modular buildings more than 25 storeys high. The concrete core should be constructed to a similar level of accuracy to avoid closure of gaps when the modules are installed later. The minimum design gap between the core and the adjacent modules is proposed as $75 \mathrm{~mm}$. In addition, it is necessary to consider the effect of movements in the modules themselves due to the loads applied to them and shrinkage and creep effects in the core, which may be significant in high-rise buildings.

\subsection{Application of equivalent horizontal forces in modular construction}

A way of assessing the stability of a group of modules is the equivalent horizontal force approach due to eccentricities of vertical load that are added to wind loading using appropriate partial factors for load combinations. This approach is presented in BS EN 1993-1-1:5.3.2 (BSI, 2004) for columns in multistorey buildings, in which the out-of-verticality of a column is taken as $L / 300$ (for a frame more than $9 \mathrm{~m}$ high), although this is modified according to the number of columns in a horizontal group. This out-of-verticality used to determine equivalent

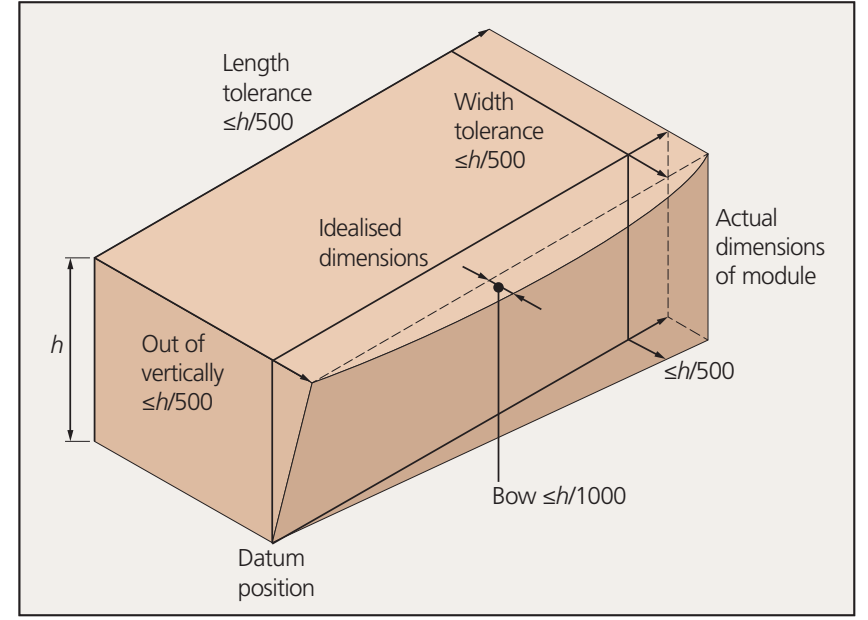

Figure 12. Maximum deviations in manufacture of modules for medium-rise buildings

horizontal forces is clearly higher than the permitted deviation in installation.

For high-rise modular construction with control of manufacturing and installation deviations as described above, it is proposed that the equivalent horizontal force acting on a module at the lowest level should be taken as not less than $0.5 \%$ of the compression force transferred from the level above. These forces may be aggregated for a number of modules at each level and transferred to the stabilising system. The amplification factor on the horizontal loads should take into account the sway stiffness of the modular system and how loads are transferred to a stiff bracing system or concrete core.

\subsection{Robustness of modular systems}

Robustness or structural integrity is the property of a structure that is concerned with avoidance of disproportionate collapse in the event of loss of a support or member. In the context of modular construction, the term 'loss of a support' would realistically mean loss of support to a corner or side of a module rather than the whole module. The worst case is that of a corner module, which means in this scenario the damaged module and those above would act as cantilevers connected to their neighbours. This leads to shear in the sides of the module due to bending and torsion actions and to horizontal and vertical tie forces between the modules. For modules connected directly to a concrete core, the same approach would apply, and in this case the connections to the core act as ties.

It might be expected that additional dynamic forces are exerted when the support to a module is lost instantaneously, and therefore a further factor should be included to ensure that the tie connections between the modules are sufficiently robust in this case. For high-rise modular buildings, it is proposed that a dynamic factor of 1.5 is applied to the static loads acting at the accidental limit state.

For the case of loss of support to a corner module, the simplified model assumes that the damaged module and the modules above can transfer their own loads by way of tying action 
(Lawson et al., 2008). In this case, the horizontal forces acting in the ties at the top or bottom of the modules are given by

$$
\text { 3. } N_{\text {tie }}=1 \cdot 5\left(G_{\mathrm{k}}+\Psi Q_{\mathrm{k}}\right) \frac{B^{2} L}{4 h}
$$

The applied load $1 \cdot 5\left(G_{\mathrm{k}}+\Psi Q_{\mathrm{k}}\right)$ is similar to the normal factored load acting on the module, which may be used to simplify the design process. For an example of a $3.6 \mathrm{~m}$ wide by $8 \mathrm{~m}$ long by $3 \mathrm{~m}$ high module with joisted floors, $G_{\mathrm{k}}=4 \mathrm{kN} / \mathrm{m}^{2}$ and $Q_{\mathrm{k}}=2 \mathrm{kN} /$ $\mathrm{m}^{2}$, in which case, $N_{\text {tie }} \approx 70 \mathrm{kN}$. The vertical tie force between the modules is taken as equal to the load transferred from a damaged module below, which is conservatively given by Equation 3 .

However, this approach to robustness is in its infancy and more research is needed on the potential forces and ductility requirements of the multiple interconnections between the modules in an extreme event. Furthermore, the tie forces acting on the adjacent modules will lead to horizontal movements and therefore to eccentricities in the compression load paths, albeit at the lower loads acting at the accidental limit state. These secondorder effects will become more important for high-rise modular buildings.

\section{Conclusions}

This paper presents case studies on recent high-rise modular buildings in terms of their important design and construction features. The case studies present the relevant module sizes and construction rates in which the modules are often supported on a podium level and stability is provided by a concrete core. The economic argument for modular construction and the different forms of manufacture influence the investment required and also the productivity that is achieved.

The effect of manufacturing and installation deviations must be taken into account in the design of modular buildings. Permitted deviations in out-of-verticality are presented for medium-rise (up to 12 storeys) and high-rise (more than 12 storeys), which in both cases should not exceed a maximum of $40 \mathrm{~mm}$ at the top floor. Using these maximum deviations, the equivalent horizontal force acting on a module at a lower level may be taken as $0.5 \%$ of the vertical load.

The robustness of modular systems may be based on a simple cantilever model for tying action between the modules. For highrise buildings, a dynamic factor is proposed to increase the loads acting at the accidental limit state in order to ensure a more robust design of the ties between the modules.

\section{Acknowledgements}

This paper uses information provided by Vision Modular, Tide Construction and Caledonian Modular as well as from practitioners in modular construction. It is dedicated to the life of Professor Ray Ogden who was a pioneer in the field of modular construction and was joint author of the book Design in Modular Construction (Lawson et al., 2014).

\section{References}

Breeam (Building Research Establishment Environmental Assessment Method) (2019) What is BREEAM? See http://www.breeam.org (accessed 23/03/2019)

BSI (2004) BS EN 1993-1-1: Eurocode 3: Steel structures. General rules and rules for buildings. BSI, London, UK.

BSI (2008) BS EN 1090-2: Execution of steel structures and aluminium structures. Part 2: Technical requirements for steel structures. BSI, London, UK.

CIC (Construction Industry Council) (2013) Offsite Housing Review. See http://www.cic.org.uk (accessed 23/03/2019).

CITB (Construction Industry Training Board) (2017) Faster, Smarter, More Efficient: Building Skills for Offsite Construction. See https://www.citb. co.uk/documents/research/offsite_construction/offsite_construction_full_ report_20170410.pdf (accessed 23/03/2019).

Farmer M (2016) The Farmer Review of the UK Construction Labour Model: Modernise or Die. CLC, London, UK.

Gibb AGF and Pendlebury MC (2006) Buildoffsite Glossary of Terms, 2nd edn (Goodier C, Ashley D and Taylor M (eds)). CIRIA, London, UK.

Goodier CI and Gibb AGF (2007) Future opportunities for offsite in the UK. Construction Management and Economics 25(6): 585-595.

House of Lords Science and Technology Select Committee (2018) 2nd report of session 2017-19. In Off-site Manufacture for Construction: Building for Change. See https://publications.parliament.uk/pa/ld201719/ldselect/ Idsctech/169/16902.htm (accessed 23/03/2019).

KPMG (2016) Smart Construction - How Offsite Manufacturing Can Transform our Industry? See https://home.kpmg/tr/en/home/ insights/2016/04/smart-construction-report.html (accessed 23/03/2019).

Lawson RM and Richards J (2010) Modular design for high-rise buildings. Proceedings of the Institution of Civil Engineers - Structures and Buildings 163(3): 151-164, https://doi.org/10.1680/stbu.2010.163.3.151.

Lawson RM, Byfield M, Popo-Ola S and Grubb PJ (2008) Robustness of light steel frames and modular construction. Proceedings of the Institution of Civil Engineers - Structures and Buildings 161(1): 3-16, https://doi. org/10.1680/stbu.2008.161.1.3.

Lawson RM, Ogden RG and Bergin R (2012) Application of modular construction in high-rise buildings. Journal of Architectural Engineering 18(2): 148-154

Lawson RM, Ogden RG and Goodier C (2014) Design in Modular Construction. CRC Press, Boca Raton, FL, USA.

Mullen MA (2011) Factory Design for Modular Home Building Constructability Press, Winter Park, FL, USA.

NAO (National Audit Office) (2005) Using Modern Methods of Construction to Build Homes More Quickly and Efficiently. See https://www.nao.org. uk/report/using-modern-methods-of-construction-to-build-homes-morequickly-and-efficiently/ (accessed 23/03/2019).

NHBC Foundation (2016) Modern Methods of Construction: Views from the Industry (NF70). See https://www.nhbcfoundation.org/publication/ modern-methods-of-construction-views-from-the-industry (accessed 23/03/2019)

UKCES (UK Commission for Employment and Skills) (2013) Technology and Skills in the Construction Industry. See https://assets.publishing service.gov.uk/government/uploads/system/uploads/attachment_data/ file/305025/Technology_and_skills_in_the_construction_industry_ executive_summary.pdf (accessed 23/03/2019).

\section{How can you contribute?}

If you would like to comment on this paper, please email up to 200 words to the editor at journals@ice.org.uk. 